\title{
Evaluation of a Low-Cost Bubble CPAP System Designed for Resource-Limited Settings
}

\author{
Desmond J Bennett, Ryan W Carroll MD MPH, and Robert M Kacmarek PhD RRT FAARC
}

BACKGROUND: Respiratory compromise is a leading contributor to global neonatal death. CPAP is a method of treatment that helps maintain lung volume during expiration, promotes comfortable breathing, and improves oxygenation. Bubble CPAP is an effective alternative to standard CPAP. We sought to determine the reliability and functionality of a low-cost bubble CPAP device designed for low-resource settings. METHODS: The low-cost bubble CPAP device was compared to a commercially available bubble CPAP system. The devices were connected to a lung simulator that simulated neonates of 4 different weights with compromised respiratory mechanics $(\sim 1, \sim 3$, $\sim 5$, and $\sim 10 \mathrm{~kg}$ ). The devices' abilities to establish and maintain pressure and flow under normal conditions as well as under conditions of leak were compared. Multiple combinations of pressure levels $\left(5,8\right.$, and $\left.10 \mathrm{~cm} \mathrm{H}_{2} \mathrm{O}\right)$ and flow levels $(3,6$, and $10 \mathrm{~L} / \mathrm{min})$ were tested. The endurance of both devices was also tested by running the systems continuously for $8 \mathrm{~h}$ and measuring the changes in pressure and flow. RESULTS: Both devices performed equivalently during the no-leak and leak trials. While our testing revealed individual differences that were statistically significant and clinically important $(>10 \%$ difference) within specific CPAP and flow-level settings, no overall comparisons of CPAP or flow were both statistically significant and clinically important. Each device delivered pressures similar to the desired pressures, although the flows delivered by both machines were lower than the set flows in most trials. During the endurance trials, the low-cost device was marginally better at maintaining pressure, while the commercially available device was better at maintaining flow. CONCLUSIONS: The low-cost bubble CPAP device evaluated in this study is comparable to a bubble CPAP system used in developed settings. Extensive clinical trials, however, are necessary to confirm its effectiveness. Key words: CPAP; bubble CPAP; respiratory distress; low-resource settings; Uganda; neonate. [Respir Care 2018;63(4):395-403. (C) 2018 Daedalus Enterprises]

\section{Introduction}

Respiratory compromise is a leading contributor to the nearly 3 million neonatal deaths that occur each year. ${ }^{1,2}$ It can result from prematurity, pneumonia, sepsis, and intrapartum-related complications, which are collectively re-

Mr Bennett and Dr Kacmarek are affiliated with the Department of Respiratory Care, Massachusetts General Hospital, Boston, Massachusetts. Dr Kacmarek is also affiliated with the Department of Anesthesia, Critical Care and Pain Medicine, Massachusetts General Hospital, and Harvard Medical School, Boston, Massachusetts. Dr Carroll is affiliated with the Department of Pediatric Critical Care Medicine, Massachusetts General Hospital, and Harvard Medical School, Boston, Massachusetts.

Dr Kacmarek has disclosed relationships with Venner Medical, Covidien, Orange Medical, and Teleflex. The other authors have disclosed no conflicts of interest. sponsible for $>80 \%$ of neonatal deaths globally. ${ }^{3,4} \mathrm{An}$ effective means of treating children with respiratory distress has the potential to impact global child mortality. In the developed world, respiratory support is administered via mechanical ventilation or CPAP, which helps maintain lung volume during expiration, promotes comfortable breathing, and improves oxygenation. ${ }^{5,6}$ However, the average stand alone CPAP machine costs more than $\$ 5,000$

\footnotetext{
This work was supported by the Respiratory Care Department at Massachusetts General Hospital.

Correspondence: Robert M Kacmarek PhD RRT FAARC, Department of Respiratory Care, Massachusetts General Hospital, 55 Fruit St, Boston, MA, 02114. E-mail: rkacmarek@mgh.harvard.edu.
}

DOI: $10.4187 /$ respcare. 05762 
$\mathrm{USD}^{7}$ and requires highly trained personnel to operate and maintain it, rendering such devices inaccessible to lowresource settings. ${ }^{2,8}$

Bubble CPAP is an alternative but effective approach to providing CPAP in which pressure is safely maintained by submerging the end of the expiratory tubing in water; the depth of the expiratory tubing dictates the amount of pressure generated. The use of bubble CPAP as well as other approaches to apply CPAP in developed countries has reduced mortality by up to $50 \%{ }^{2,9}$ and has reduced morbidity and days in hospital. ${ }^{10}$ Studies have shown that the use of bubble CPAP can be equally effective in low-resource settings, but such settings necessitate inexpensive and easily repairable devices. ${ }^{5,7,11-13}$

A simple, low-cost bubble CPAP device was developed by staff at Massachusetts General Hospital in Boston, Massachusetts. The device, designed for the low-resource settings of Uganda, is composed of only 6 major parts $(\sim 25$ parts in total), and the expected cost is nearly 50 times less than the average stand alone CPAP device. With appropriate sterilization/disinfection, all aspects of the device can be reused. Because of its expected low cost and relative simplicity, the device has the potential to impact pediatric mortality in Uganda, which has a neonatal mortality rate of 19 per 1,000 live births and an infant mortality rate of 38 per 1,000 live births. ${ }^{1}$ However, the device's function has yet to be independently verified. Using simulated models of children with compromised respiratory mechanics, we assessed the accuracy and reliability of the lowcost bubble CPAP device by comparing it to the $\mathrm{B} \& \mathrm{~B}$ Bubbler (B\&B Medical Technologies, Carlsbad, California), a commercially available bubble CPAP system. We hypothesized that the low-cost bubble CPAP system would function equivalently to the B\&B Bubbler without demonstrating clinically important differences.

\section{Methods}

This study was funded by and performed in the Department of Respiratory Care, Massachusetts General Hospital (Boston, Massachusetts).

\section{The Device}

The low-cost bubble CPAP device consists of relatively few components (see Fig. 1), with a total cost of roughly $\$ 110$ USD. The system includes an ambient air compressor, an adjustable flow meter (Dwyer Instruments, Michigan City, Indiana), a pressure regulator (a bubble PEEP valve), inspiratory and expiratory tubing (Finger Lakes Extrusion, Canandaigua, New York), and a water bottle with a RAM cannula (Neotech, Valencia, California); it should be noted that this cannula, though used extensively for CPAP, is not cleared by the Food and Drug Adminis-

\section{QUICK LOOK}

\section{Current knowledge}

Respiratory compromise is a leading cause of neonatal mortality, and CPAP is an effective treatment. However, standard CPAP setups are expensive and inaccessible to low-resource settings. Bubble CPAP is an alternative approach to CPAP that has been shown to be effective in low-resource settings.

\section{What this paper contributes to our knowledge}

In a simulated lung model setting, the low-cost bubble CPAP device provided similar pressures and flows to that of a standard bubble CPAP device. Over a prolonged period of time, flow dropped significantly, but pressure did not.

tration for this purpose. The adjustable flow system provides a continuous flow of room air, and the bubble PEEP valve maintains the pressure delivered to the patient. This bubble CPAP device, in its current design, does not accommodate an external source of oxygen, so blended oxygen delivery is not possible.

\section{The Evaluation}

This study was performed in 3 parts. In the first part, we used a lung simulator to test the devices' abilities to establish and maintain pressure and flow under normal conditions as well as under conditions of leak. In the second part, we tested the devices' abilities to deliver flow when attached to a ventilator tester rather than a lung simulator. In the final part, we measured the devices' endurance. For comparison purposes, all trials of this study were conducted using both the low-cost bubble CPAP device and the B\&B Bubbler system. When using the B\&B Bubbler, a DAC1 dry-air compressor (Siemens, Munich, Germany) was used to generate flow.

\section{Evaluating Pressure and Flow}

Using a Lung Simulator Without Leak. Each bubble CPAP device was tested at 3 levels of pressure $(5,8$, and $10 \mathrm{~cm} \mathrm{H}_{2} \mathrm{O}$ ), and 3 flows $(3,6$, and $10 \mathrm{~L} / \mathrm{min})$ were set at each pressure for each of the premature infant weights simulated. Each device was connected to the ASL 5000 breathing simulator (v3.5, IngMar Medical, Pittsburgh, Pennsylvania), which was preprogrammed to simulate preemies of 4 different weights (Table 1). The lung mechanics for each simulated model were determined from previous clinical ${ }^{14-17}$ and simulation ${ }^{18-21}$ studies, with specific 


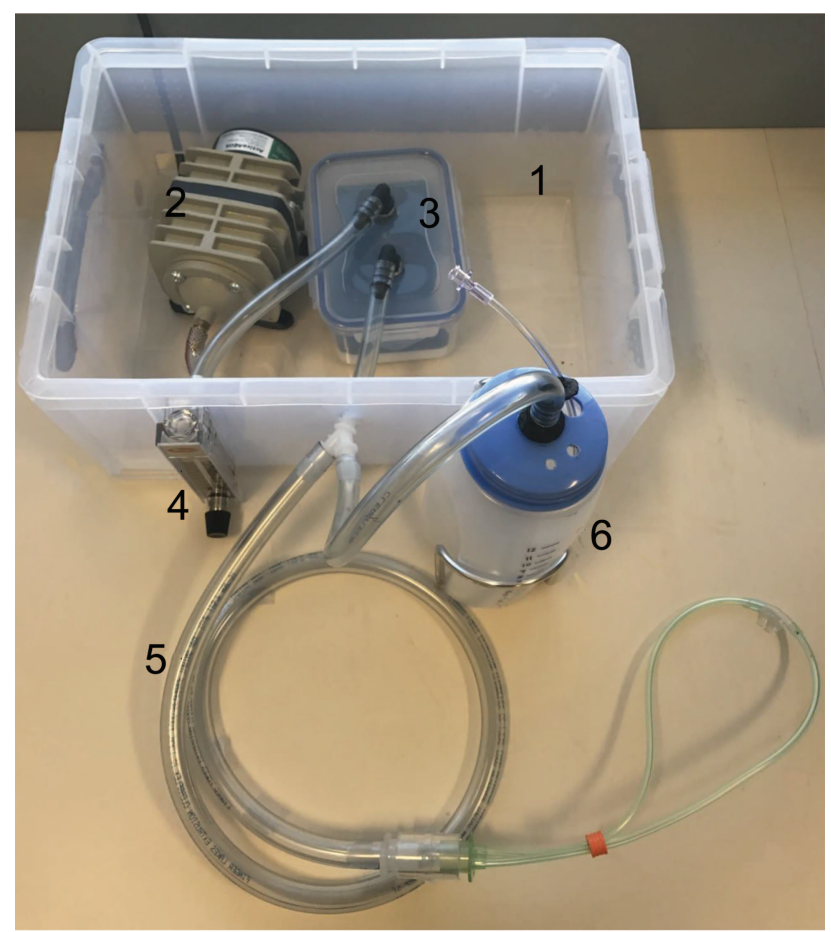

Fig. 1. The low-cost bubble CPAP system. (1) A 10-L, rectangular, plastic housing box. (2) A 45-L/min air pump. (3) A water-filled plastic container used for humidification (a foam space filler was used instead of water in our experiments to minimize potential damage to electronic testing devices). (4) A 10-L/min flow meter. (5) Airway tubing. (6) A water bottle (height $>10 \mathrm{~cm}$ ) with a RAM cannula attached to the low-cost bubble CPAP device.

references ${ }^{15,16,19,20}$ used for airway occlusion pressure $\left(\mathrm{P}_{0.1}\right)$ and maximum inspiratory pressure. To simulate a trachea, we placed an endotracheal tube between the bubble CPAP circuit and the test lung. Trachea diameter and length were determined from previous clinical studies $22-24$ (Table 2).

The ASL 5000 was used in this evaluation because of its precision in reproducing a consistent ventilatory pattern during all evaluations. In addition, the 4 neonatal lung models studied could be easily set with the ASL 5000. The ASL 5000 also measures, records, and displays pressures and flow within the simulated respiratory system.

The 9 possible combinations of pressure and flow were run with all 4 simulated pediatric patients $(\sim 1, \sim 3, \sim 5$, and $\sim 10 \mathrm{~kg}$ ), resulting in a total of 36 trials, each lasting 15 min. Peak inspiratory flow and PEEP were compared between the 2 devices.

Using a Lung Simulator With Leak. To simulate nasal prong leak, we used a stopcock to introduce a $20 \%$ leak ${ }^{18,25,26}$ at the distal end of the bubble CPAP delivery system. Peak inspiratory flow and PEEP were compared between the 2 devices. The system pressures, flows, and lung models from the test without leak were used in the test with leak.

\section{Evaluating Flow Using a Ventilator Tester}

To test the devices' flow when resistors (stiff lungs) were not present, we attached each device to a PTS 2000 ventilator tester (Mallinckrodt, Dublin, Ireland), which measured both systems' flows. CPAP was set to $5 \mathrm{~cm} \mathrm{H}_{2} \mathrm{O}$, and tests were performed at each of the following rates: 2 , 4, 6, 8, and $10 \mathrm{~L} / \mathrm{min}$ for $10 \mathrm{~min}$. The PTS 2000 was used because of its accuracy and precision in the measurement of flow and pressure gradients.

\section{Evaluating Endurance}

To evaluate the devices' abilities to maintain pressure and flow over a prolonged period of time, we ran them continuously for $8 \mathrm{~h}$. CPAP was set at $8 \mathrm{~cm} \mathrm{H}_{2} \mathrm{O}$, and flow was set to $6 \mathrm{~L} / \mathrm{min}$. For the first and the last $10 \mathrm{~min}$, the devices were connected to the ASL 5000 breathing simulator and the PTS 2000 ventilator tester so that pressure and flow data, respectively, could be collected. To avoid any accidental condensation entering the ASL 5000 or the PTS 2000 from the bubble CPAP, the devices were connected to a simpler, non-computerized test lung during the middle $7 \mathrm{~h}$ and $40 \mathrm{~min}$ to capture condensate. Because some water did evaporate from the PEEP bottles over the 8-h period, we measured the drop in water height so pressure changes could be accounted for.

Finally, a temperature probe was placed on top of the humidifier chamber of the low-cost bubble CPAP device to measure the system's temperature increase. For both the temperature and longevity tests, a total of three 8 -h trials were run.

\section{Statistical Analysis}

Pressure data were collected using the lung simulator's software (ASL software version 3.5, IngMar Medical) while flow data were collected by both the lung simulator's software and the PTS 2000's software (BreathLab PTS software v2.0, Mallinckrodt). Results are expressed as mean values $\pm \mathrm{SD}$, and means were compared using 2-way $t$ tests. The change in water levels between the 2 systems during the endurance test were compared using a 2-way $t$ test. Statistical analysis was conducted using R Statistical Software (R Foundation for Statistical Computing, Vienna, Austria). A value of $P<.05$ was considered statistically significant. We have reported all results, but we only discuss differences that were both statistically significant $(P<.05)$ and clinically important $(>10 \%$ difference).

Differences in performance between the 2 devices were not considered clinically important unless the differences were both significant and $>10 \%$. We used this approach because lung-model studies generate a large number of 


\section{Evaluation of Low-Cost Bubble CPAP}

Table 1. Lung Model Settings

\begin{tabular}{|c|c|c|c|c|c|c|}
\hline $\begin{array}{l}\text { Model (Approximate } \\
\text { Weight) }\end{array}$ & $\begin{array}{c}\mathrm{P}_{0.1} \\
\mathrm{~cm} \mathrm{H}_{2} \mathrm{O}\end{array}$ & $\mathrm{P}_{\max } \mathrm{cm} \mathrm{H}_{2} \mathrm{O}$ & $\begin{array}{l}\text { Resistance, } \\
\mathrm{cm} \mathrm{H} \mathrm{H}_{2} \mathrm{O} / \mathrm{L} / \mathrm{s}\end{array}$ & $\begin{array}{l}\text { Compliance, } \\
\mathrm{mL} / \mathrm{cm} \mathrm{H}_{2} \mathrm{O}\end{array}$ & $\begin{array}{c}\text { Breathing Frequency, } \\
\text { Breaths/min }\end{array}$ & $\begin{array}{c}\text { Inspiratory } \\
\text { Time, ms }\end{array}$ \\
\hline Preemie $(\sim 1 \mathrm{~kg})$ & 2 & 4 & 100 & 1 & 60 & 300 \\
\hline Newborn $(\sim 3 \mathrm{~kg})$ & 3 & 6 & 70 & 4 & 50 & 375 \\
\hline Infant $(\sim 5 \mathrm{~kg})$ & 4 & 8 & 50 & 6 & 40 & 450 \\
\hline Pediatric $(\sim 10 \mathrm{~kg})$ & 5 & 10 & 25 & 10 & 30 & 600 \\
\hline
\end{tabular}

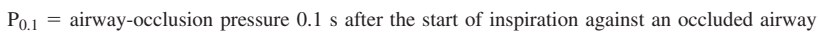

$\mathrm{P}_{\max }=$ maximum inspiratory pressure drop

Table 2. $\quad$ Simulated Trachea Settings

\begin{tabular}{lcc}
\hline $\begin{array}{c}\text { Model (Approximate } \\
\text { Weight) }\end{array}$ & $\begin{array}{c}\text { Trachea } \\
\text { Diameter, mm }\end{array}$ & $\begin{array}{c}\text { Trachea } \\
\text { Length, } \mathrm{cm}\end{array}$ \\
\hline Preemie $(\sim 1 \mathrm{~kg})$ & 3.0 & 3.5 \\
Newborn $(\sim 3 \mathrm{~kg})$ & 3.5 & 4.0 \\
Infant $(\sim 5 \mathrm{~kg})$ & 4.0 & 4.5 \\
Pediatric $(\sim 10 \mathrm{~kg})$ & 5.0 & 5.5 \\
\hline
\end{tabular}

data points, and when 2 machines are compared, statistically significant differences may have no clinical relevance. We therefore chose to use a $10 \%$ difference to imply clinical importance because this is the tolerance of most settings and measurements on mechanical ventilators. For example, a ventilator set to deliver a tidal volume of $500 \mathrm{~mL}$ may generate a breath between 450 and $550 \mathrm{~mL}$, which is considered an acceptable level of accuracy. Thus, we assumed a difference $>10 \%$ should raise a concern regarding the performance of devices being compared.

\section{Results}

\section{Evaluating Pressure and Flow}

Using a Lung Simulator With No Leak. Across all body weights and flows, the $\mathrm{B} \& \mathrm{~B}$ Bubbler generated higher PEEP than the low-cost bubble CPAP device at the $5 \mathrm{~cm}$ $\mathrm{H}_{2} \mathrm{O}$ CPAP level $\left(5.68 \pm 0.46\right.$ vs $5.24 \pm 0.21 \mathrm{~cm} \mathrm{H}_{2} \mathrm{O}$, $P<.01$ ), but the low-cost bubble CPAP device generated higher PEEP than the B\&B at CPAP levels 8 and $10 \mathrm{~cm}$ $\mathrm{H}_{2} \mathrm{O}$ (B\&B Bubbler vs low-cost bubble CPAP device: $8.21 \pm 0.74$ vs $8.26 \pm 0.19 \mathrm{~cm} \mathrm{H}_{2} \mathrm{O}, P=.70$; and $9.65 \pm 0.38$ vs $10.13 \pm 0.22 \mathrm{~cm} \mathrm{H}_{2} \mathrm{O}, P=0.008$, respectively). While individual PEEP comparisons were found to be statistically significant and clinically important, the overall PEEP comparisons of the 2 systems were not found to be both statistically significant and clinically important (Fig. 2A).

Across all body weights and CPAP levels, the B\&B Bubbler delivered lower flows at each of the 3 flow settings (B\&B Bubbler vs low-cost bubble CPAP device:
$3.41 \pm 1.73$ vs $3.75 \pm 2.01 \mathrm{~L} / \mathrm{min}, P=.66 ; 4.43 \pm 2.53$ vs $4.71 \pm 2.74 \mathrm{~L} / \mathrm{min}, P=.79$; and $5.20 \pm 3.42$ vs $5.48 \pm 3.36 \mathrm{~L} / \mathrm{min}, P=.84$ ). While individual flow comparisons were found to be statistically significant and clinically important, the overall flow comparisons of the 2 systems were not found to be both statistically significant and clinically important (Fig. 2B).

Using a Lung Simulator With 20\% Leak. Across all body weights and flows, the $\mathrm{B} \& \mathrm{~B}$ Bubbler generated higher PEEP at the $5 \mathrm{~cm} \mathrm{H}_{2} \mathrm{O}$ CPAP level (B\&B Bubbler vs lowcost bubble CPAP device: $5.19 \pm 0.36$ vs $5.11 \pm 0.26 \mathrm{~cm}$ $\mathrm{H}_{2} \mathrm{O}, P=.54$ ), but the $\mathrm{B} \& \mathrm{~B}$ Bubbler generated lower PEEP at CPAP levels 8 and $10 \mathrm{~cm} \mathrm{H}_{2} \mathrm{O}$ (B\&B Bubbler vs low-cost bubble CPAP device: $7.50 \pm 1.05$ vs $8.09 \pm 0.36 \mathrm{~cm} \mathrm{H}_{2} \mathrm{O}$, $P=.08$; and $8.73 \pm 1.79$ vs $9.84 \pm 0.95 \mathrm{~cm} \mathrm{H}_{2} \mathrm{O}, P=.07$, respectively). While individual PEEP comparisons were found to be statistically significant and clinically important, the overall PEEP comparisons of the 2 systems were not found to be both statistically significant and clinically important (Fig. 3A).

The B\&B bubbler and the low-cost bubble CPAP device delivered average flows of $3.04 \pm 2.05 \mathrm{~L} / \mathrm{min}$ and $3.04 \pm 1.85(P=.10)$ at the $3 \mathrm{~L} / \mathrm{min}$ flow setting, respectively, but the $\mathrm{B} \& \mathrm{~B}$ Bubbler delivered lower flows at the 6 and $10 \mathrm{~L} / \mathrm{min}$ settings (B\&B Bubbler vs low-cost bubble CPAP device: $3.61 \pm 1.88$ vs $3.81 \pm 1.98 \mathrm{~L} / \mathrm{min}, P=.81$; and $4.55 \pm 2.53$ vs $4.95 \pm 2.7 \mathrm{~L} / \mathrm{min}, P=.72$, respectively). While individual flow comparisons were found to be statistically significant and clinically important, the overall flow comparisons of the 2 systems were not found to be both statistically significant and clinically important (Fig. 3B).

\section{Evaluating Flow Using a Ventilator Tester}

The B\&B Bubbler and the low-cost bubble CPAP device generated similar flows when not connected to a lung; no comparisons were both statistically significant and clinically important (Fig. 4). 

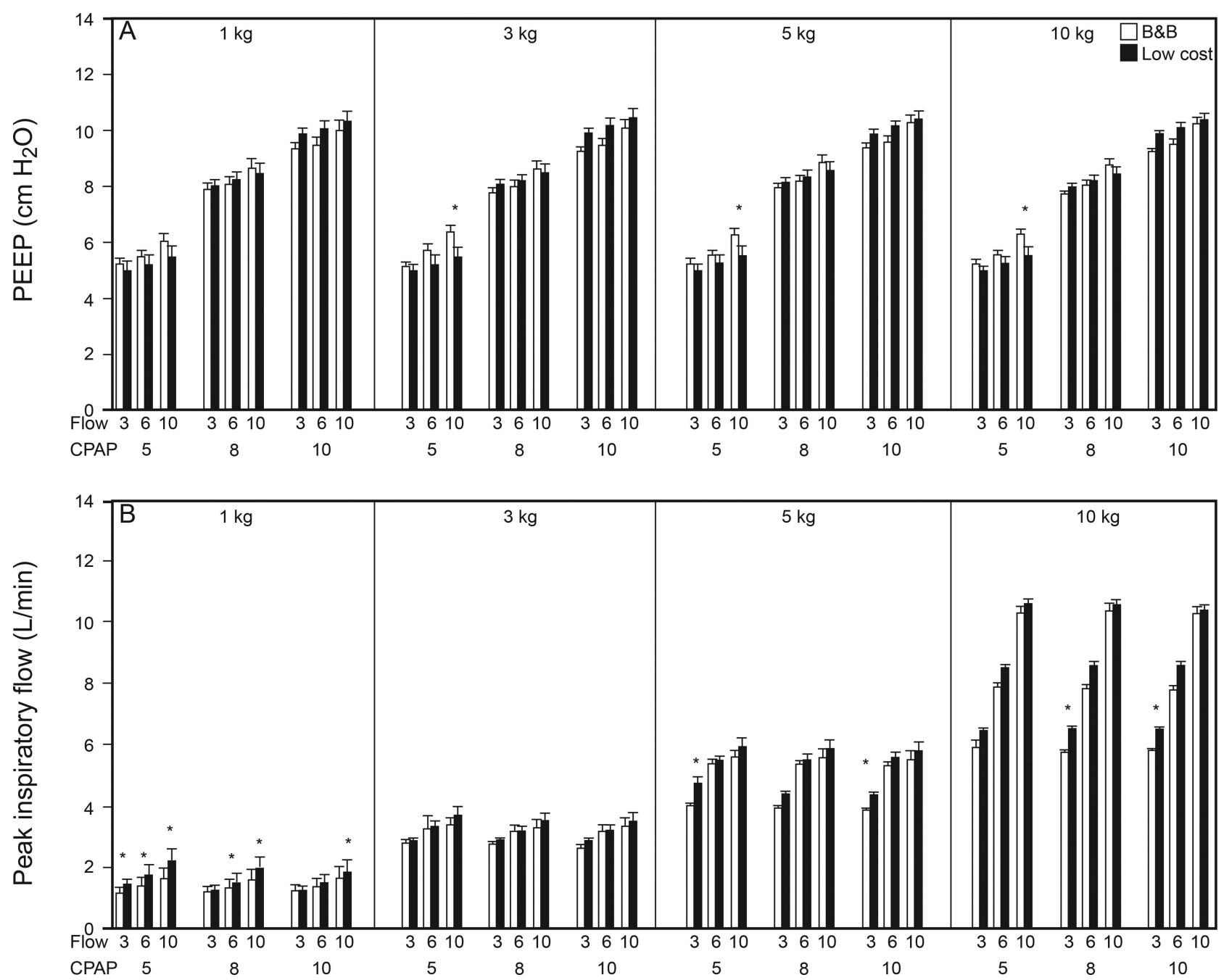

Fig. 2. PEEP and flow comparisons, with no leak. (A) PEEP comparisons. (B) Flow comparisons. *Indicates the comparison was both statistically significant and represented $a>10 \%$ difference.

\section{Evaluating Endurance}

Over $8 \mathrm{~h}$ (set PEEP $8 \mathrm{~cm} \mathrm{H}_{2} \mathrm{O}$ ), the PEEP generated by the $\mathrm{B} \& \mathrm{~B}$ Bubbler dropped from an average of $8.27 \pm 0.26 \mathrm{~cm} \mathrm{H}_{2} \mathrm{O}$ to $7.49 \pm 0.24 \mathrm{~cm} \mathrm{H}_{2} \mathrm{O}$, with an average decrease in water level of $0.5 \pm 0.1 \mathrm{~cm}$ (Fig. 5A). The PEEP from the low-cost bubble CPAP device dropped from $8.27 \pm 0.28 \mathrm{~cm} \mathrm{H}_{2} \mathrm{O}$ to $7.57 \pm 0.25 \mathrm{~cm} \mathrm{H}_{2} \mathrm{O}$, with an average decrease in water level of $0.7 \pm 0.2 \mathrm{~cm}$. When accounting for the drop in water level, the larger decrease by the $\mathrm{B} \& \mathrm{~B}$ was statistically significant $(P<.001)$ and clinically important ( $>10 \%$ difference).

The flow generated by the B\&B Bubbler dropped from $6.01 \pm 0.03$ to $5.83 \pm 0.06 \mathrm{~L} / \mathrm{min}$, and the flow from the low-cost bubble CPAP device dropped from $6.00 \pm 0.06$ to $5.51 \pm 0.04 \mathrm{~L} / \mathrm{min}$ (Fig. 5B). The larger decrease exhibited by the low-cost bubble CPAP device was both statistically significant $(P<.001)$ and clinically important $(>10 \%$ difference).
The low-cost bubble CPAP device's flow pump itself reached a max temperature of $119 \pm 3.0^{\circ} \mathrm{F}\left(48.3 \pm 1.7^{\circ} \mathrm{C}\right)$, but the starting temperature inside the container was $75.0 \pm 1.0^{\circ} \mathrm{F}\left(23.9 \pm 0.6^{\circ} \mathrm{C}\right)$ and rose to $97.0 \pm 1.0^{\circ} \mathrm{F}$ $\left(36.1 \pm 0.6^{\circ} \mathrm{C}\right)$ after $8 \mathrm{~h}$ of continuous use.

\section{Discussion}

The main findings of this study are that the low-cost bubble CPAP device was capable of delivering pressures and flows equivalent to that of the commercially available B\&B Bubbler system, and that the low-cost bubble CPAP device was marginally better at maintaining pressure over a prolonged period of time, but worse at maintaining flow.

Our results demonstrate that, overall, the low-cost bubble CPAP system is able to deliver pressures and flows equivalent to those of bubble CPAP systems used in developed settings. However, there were several individual 

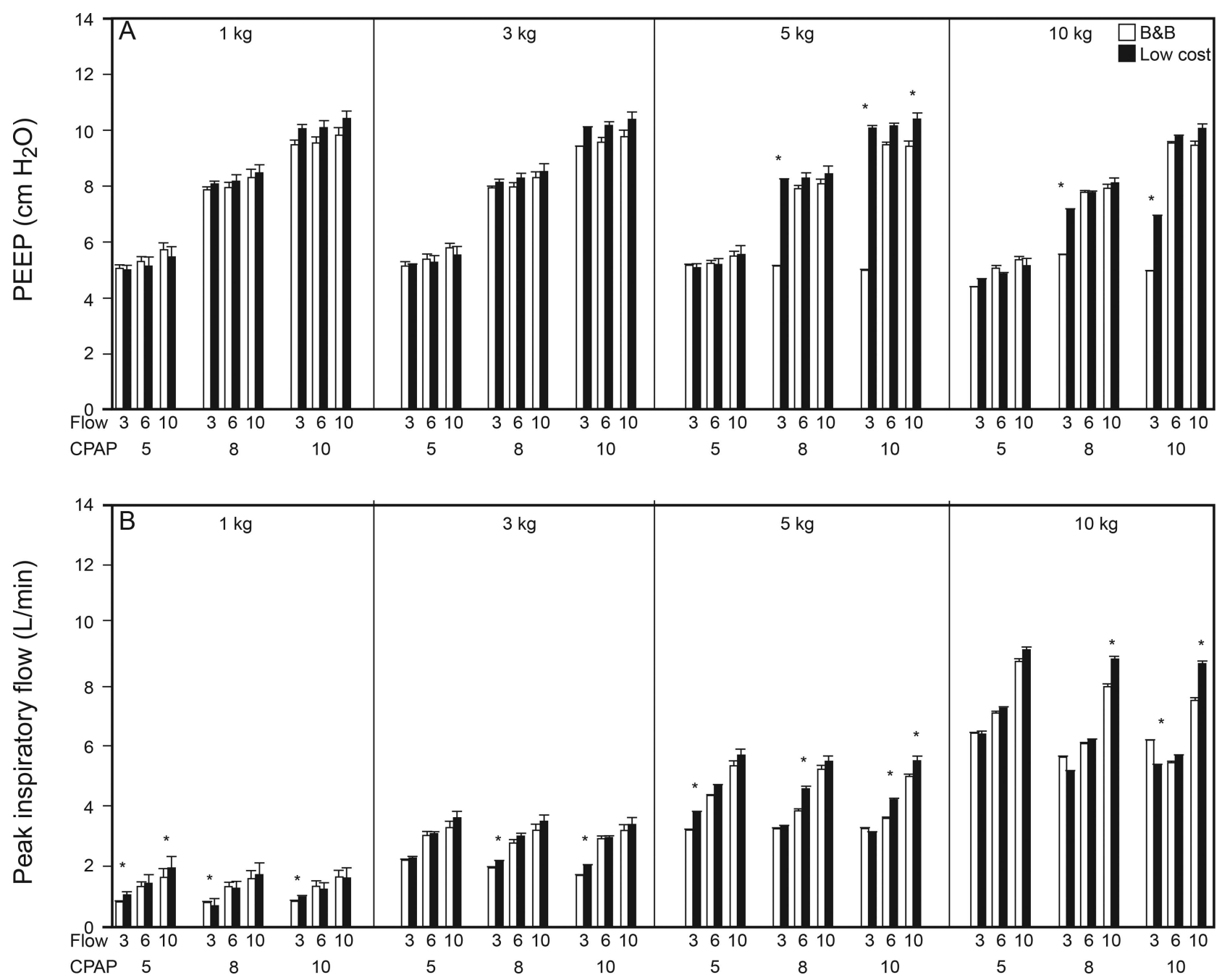

Fig. 3. PEEP and flow comparisons with $20 \%$ leak. (A) PEEP comparisons. (B) Flow comparisons. *Indicates the comparison was both statistically significant and represented $a>10 \%$ difference.

comparisons that reached statistical significance and represented a $>10 \%$ difference. The differences in pressure generated by the 2 devices could be due to the simple method of water-depth measurement on the low-cost bubble CPAP device. The water-depth levels were measured with a ruler, and each line was marked with a pen, which could create slight variability in the actual volume measurement. The differences in both pressure and flow could also be due to the different respiratory circuits used with each system. Kahn et al ${ }^{26}$ compared delivered versus intended intra-prong, proximal-airway, and distal-airway pressures of a bubble CPAP device and found that delivered pressures at both the intra-prong and proximal-airway overshot the intended CPAP level, which could be due to the resistance of the exhalation arm of the circuit tubing. During the exhalation phase of the respiratory cycle, the patient exhales into the circuit tubing, which has its own intrinsic resistance, creating an increase in pressure sustaining the CPAP level. In our study, the B\&B Bubbler system's tubing differed from that of the low-cost bubble CPAP device, which could explain the slight differences in pressure and flow at some settings.

Both devices delivered $3.04 \mathrm{~L} / \mathrm{min}$ of flow at the $3-\mathrm{L} / \mathrm{min}$ setting. However, at the 6 - and $10-\mathrm{L} / \mathrm{min}$ settings, the delivered flows were no higher than 3.81 and $4.95 \mathrm{~L} / \mathrm{min}$, respectively. The ability to maintain delivered flow with either of these devices is a concern and may present a clinical issue with larger patients demanding greater flows. The test lung models were designed to simulate compromised respiratory mechanics (low compliances and high resistances), and the delivered flows were much lower than the set flows. When the test lung was not present, both devices were capable of flow output equivalent to the desired flow (Fig. 4), but with highly resistive lungs, the deliverable flow began to plateau. 
The low-cost bubble CPAP device maintained pressure over a prolonged period more effectively than the $\mathrm{B} \& \mathrm{~B}$ Bubbler system, but the difference in pressure was $<0.3 \mathrm{~cm} \mathrm{H} \mathrm{H}_{2} \mathrm{O}$, which is likely not substantial in an actual clinical setting. It is important to note, however, that users of either device should be aware of the potential for a decrease in water level in the PEEP bottle over extended periods of time due to rapid bubbling and evaporation. Vigilance and diligent replacement of water are recommended with either unit. The flow dropped significantly more with the low-cost bubble CPAP device, which is likely due to the $45-\mathrm{L} / \mathrm{min}$ air pump (Active Aqua Pump, Hydrofarm, Petaluma, California) used in the device. The pump reached a maximum temperature of $119^{\circ} \mathrm{F}\left(48.3^{\circ} \mathrm{C}\right)$; while this temperature was not high enough to evoke safety concerns, the pump may require a more robust cooling system. It is possible that as the motor temperature increases, the pump's efficiency decreases.

While the motor generated heat, the temperature in the container itself remained near body temperature and did not pose a threat because the temperature of the delivered gas cooled as it moved though the circuit to the patient.

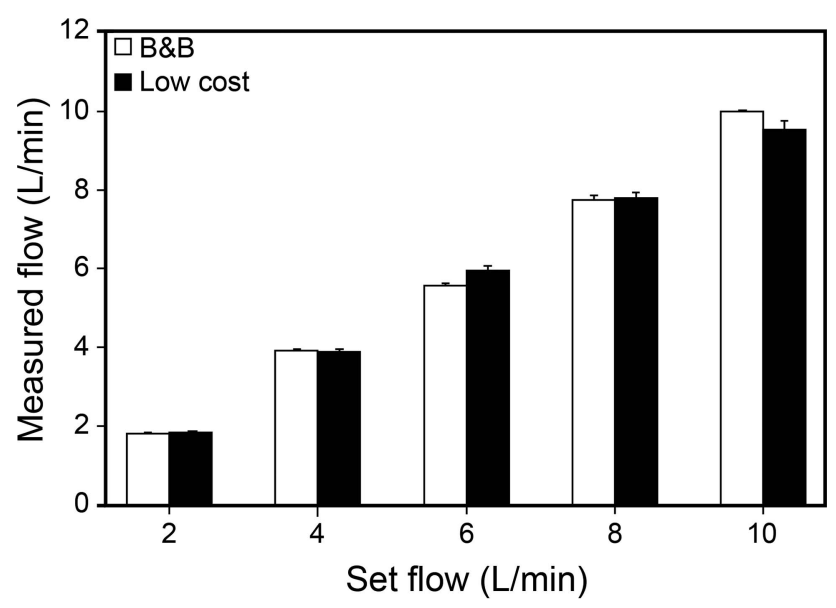

Fig. 4. Flow capability comparison for a B\&B device and a lowcost bubble CPAP system when not connected to a test lung.

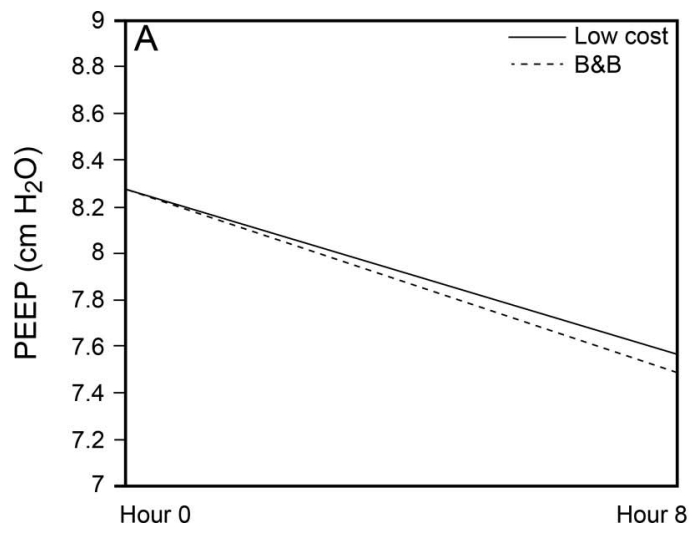

Flow generation in developed settings can be accomplished with much more complex pumps, which have better cooling mechanics and may not lose as much effectiveness over time. Providers using the low-cost bubble CPAP device in low-resource settings must be aware of the potential for a drop in flow.

The low-cost bubble CPAP device does not have all of the features standard to bubble CPAP devices in developed settings. Most notably, this device does not have a port for an external source of oxygen, so blended delivery is not possible. We recommend oxygen blending be made possible in the next iteration of the device.

The tested low-cost bubble CPAP device is expected to be less expensive than other low-cost bubble CPAP devices designed for low-resource settings. A bubble CPAP device was developed for implementation in Malawi, which included an additional attachment that allowed the blending of oxygen from an oxygen source. ${ }^{8}$ In comparison, however, it did not heat or humidify the air mix delivered to the patient. The low-cost bubble CPAP device in this study humidifies the air via an in-line water chamber, which is heated indirectly by the system itself. An important consideration is whether the end-user will always have access to clean water to be used in the humidification chamber. It is recommended that humidification water sources be changed frequently and the chamber be sanitized according to local standards.

Nahimana et $\mathrm{al}^{6}$ assessed provider adherence to standard bubble CPAP protocol in district hospitals in Rwanda and found that providers correctly identified only $59 \%$ of infants eligible for bubble CPAP, and only $52 \%$ of infants eligible for bubble CPAP received this treatment. Correct identification of a child who may benefit from CPAP, and its subsequent initiation, are potential problems in lowresource settings; as a result, there have been efforts to improve training. Hundalani et $\mathrm{al}^{3}$ developed a simple algorithm for use in low-income settings that helps identify neonates who could benefit from CPAP. They found that

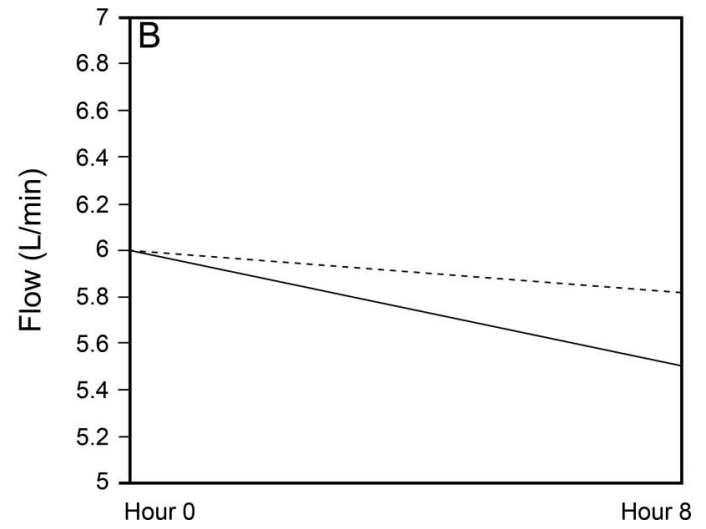

Fig. 5. PEEP (A) and flow changes (B) over $8 \mathrm{~h}$ comparing a B\&B device and a low-cost bubble CPAP system. 


\section{Evaluation of Low-Cost BubBle CPAP}

their algorithm has strong potential to improve the rates of correctly identifying infants in need of CPAP in provincial hospitals. Similarly, McAdams et al $^{27}$ sought to implement a low-cost bubble CPAP device in a Ugandan neonatal ICU after a short training period in which neonatal ICU staff were taught to employ the Silverman-Andersen respiratory severity score, ${ }^{28}$ a bedside exam used for assessing the level of respiratory distress in neonates. The group found that neonatal ICU staff easily learned the respiratory severity score and were able to maintain the assessment tool over time. With increased identification of neonates in need of CPAP, devices become all the more necessary and impactful.

Many studies ${ }^{5-7,11,12,29}$ have shown CPAP to be an effective treatment in low-resource settings, but complex CPAP machines are expensive and require a high level of expertise to administer and maintain. Therefore, a simple, inexpensive device is needed. Koyamaibole et $\mathrm{al}^{30}$ described the benefits of bubble CPAP in Fiji but stated, "A challenge for the biomedical industry is to manufacture an inexpensive appropriate technology model for further evaluation in developing countries." The low-cost device evaluated in this study could be the answer.

There are 2 limitations to this study. First, we did not assess the availability of the resources needed to assemble this device in areas where it would be implemented. Second, this study used a model test lung, not subjects, which raises the question of whether the findings are clinically important. To fully validate the device's functionality, clinical studies should be conducted.

\section{Conclusions}

The low-cost bubble CPAP device evaluated in this study is comparable to a bubble CPAP system used in the developed world. An extensive clinical trial is necessary to validate its effectiveness, but our evaluation suggests that the device has the potential to deliver adequate pressures and flows to treat children with compromised respiratory mechanics, and that this device is inexpensive enough to do so in low-resource settings.

\section{REFERENCES}

1. United Nations Children's Fund (UNICEF), World Health Organization (WHO), The World Bank. Levels and trends in child mortality: report 2015. New York: UNICEF; 2015.

2. Kamath BD, Macguire ER, McClure EM, Goldenberg RL, Jobe AH. Neonatal mortality from respiratory distress syndrome: lessons for low-resource countries. Pediatrics 2011;127(6):1139-1146.

3. Hundalani SG, Richards-Kortum R, Oden M, Kawaza K, Gest A, Molyneux E. Development and validation of a simple algorithm for initiation of CPAP in neonates with respiratory distress in Malawi. Arch Dis Child Fetal Neonatal Ed 2015;100(4):F332F326.
4. World Health Organization. Causes of deaths among children under 5 years, 2015. Geneva, Switzerland: World Health Organization; 2016.

5. Duke T. CPAP: a guide for clinicians in developing countries. Paediatr Int Child Health 2014;34(1):3-11.

6. Nahimana E, Ngendahayo M, Magge H, Odhiambo J, Amoroso CL, Muhirwa E, et al. Bubble CPAP to support preterm infants in rural Rwanda: a retrospective cohort study. BMC Pediatr 2015; 15:135.

7. Kawaza K, Machen HE, Brown J, Mwanza Z, Iniguez S, Gest A, et al. Efficacy of a low-cost bubble CPAP system in treatment of respiratory distress in a neonatal ward in Malawi. PLoS One 2014; 9(1):e86327.

8. Brown J, Machen H, Kawaza K, Mwanza Z, Iniguez S, Lang H, et al. A high-value, low-cost bubble continuous positive airway pressure system for low-resource settings: technical assessment and initial case reports. PLoS One 2013;8(1):e53622.

9. Dunn PM. Respiratory distress syndrome. Continuous positive airway pressure (CPAP) using the Gregory box. Proc R Soc Med 1974; 67(4):245-247.

10. De Klerk AM, De Klerk RK. Nasal continuous positive airway pressure and outcomes of preterm infants. J Paediatr Child Health 2001; 37(2):161-167.

11. Chen A, Deshmukh AA, Richards-Kortum R, Molyneux E, Kawaza $\mathrm{K}$, Cantor SB. Cost-effectiveness analysis of a low-cost bubble CPAP device in providing ventilatory support for neonates in Malawi - a preliminary report. BMC Pediatr 2014;14:288.

12. Thukral A, Sankar MJ, Chandrasekaran A, Agarwal R, Paul VK. Efficacy and safety of CPAP in low- and middle-income countries. J Perinatol 2016;36(Suppl 1):S21-S28.

13. Walk J, Dinga P, Banda C, Msiska T, Chitsamba E, Chiwayula N, et al. Non-invasive ventilation with bubble CPAP is feasible and improves respiratory physiology in hospitalised Malawian children with acute respiratory failure. Paediatr Int Child Health 2016; 36(1):28-33.

14. Gerhardt T, Hehre D, Feller R, Reifenberg L, Bancalari E. Pulmonary mechanics in normal infants and young children during first 5 years of life. Pediatr Pulmonol 1987;3:309-316.

15. Manczur TI, Greenough A, Pryor D, Rafferty GF. Assessment of respiratory drive and muscle function in the pediatric intensive care unit and prediction of extubation failure. Pediatr Crit Care Med 2000;1(2):124-126.

16. Stark AR, Goldman MD, Frantz III ID. Lung volume changes, occlusion pressure, and chest well configuration in human infants. Pediat Res 1979;13:250-256.

17. Villar J, Cheikh Ismail L, Victora CG, Ohuma EO, Bertino E, Altman DG, et al. International standards for newborn weight, length, and head circumference by gestational age and sex: the Newborn Cross-Sectional Study of the INTERGROWTH-21st Project. Lancet 2014;384(9946):857-868.

18. Iyer NP, Chatburn R. Evaluation of a nasal cannula in noninvasive ventilation using a lung simulator. Respir Care 2015;60(4):508-512.

19. Oto J, Chenelle CT, Marchese AD, Kacmarek RM. A comparison of leak compensation during pediatric noninvasive ventilation: a lung model study. Respir Care 2014;59(2):241-251.

20. Itagaki T, Chenelle CT, Bennett DJ, Fisher DF, Kacmarek RM. Effects of leak compensation on patient-ventilator synchrony during premature/neonatal invasive and noninvasive ventilation: a lung model study. Respir Care 2017;62(1):22-33.

21. Itagaki T, Bennett DJ, Chenelle CT, Fisher DF, Kacmarek RM. Performance of leak compensation in all-age ICU ventilators during volume-targeted neonatal ventilation: a lung model study. Respir Care 2017;62(1):10-21. 


\section{Evaluation of Low-Cost Bubble CPAP}

22. Griscom NT, Wohl ME. Dimensions of the growing trachea related to age and gender. AJR Am J Roentgenol 1986;146(2):223-227.

23. Lee KS, Yang CC. Tracheal length of infants under three months old. Ann Otol Rhinol Laryngol 2001;110(3):268-270.

24. Wheeler DS, Wong HR, Shanley TP. Assessment and management of the pediatric airway. In: Pediatric Critical Care Medicine: Basic Science and Clinical Evidence. Berlin, Germany: Springer Science \& Business Media 2007:223-252.

25. Podgorak T, Vines D, Dapkus J, Manaila D. 450: Comparison of percent leak using the RAM cannula in noninvasive ventilation in an infant lung model. Crit Care Med 2012;40(12 Suppl 1):1-328.

26. Kahn DJ, Courtney SE, Steele AM, Habib RH. Unpredictability of delivered bubble nasal continuous positive airway pressure: role of bias flow magnitude and nares-prong air leaks. Pediatr Res 2007; 62(3):343-347.
27. McAdams RM, Hedstrom AB, DiBlasi RM. Implementation of bubble CPAP in a rural Ugandan neonatal ICU. Respir Care 2015;60(3): 437-445.

28. Silverman WA, Andersen DH. A controlled clinical trial of effects of water mist on obstructive respiratory signs, death rate and necropsy findings among premature infants. Pediatrics 1956;17(1): $1-10$.

29. Myhre J, Immaculate M, Okeyo B, Anand M, Omoding A, Myhre L, et al. Effect of treatment of premature infants with respiratory distress using low-cost bubble CPAP in a rural African hospital. J Trop Pediatr 2016;62(5):385-389.

30. Koyamaibole L, Kado J, Qovu JD, Colquhoun S, Duke T. An evaluation of bubble-CPAP in a neonatal unit in a developing country: effective respiratory support that can be applied by nurses. J Trop Pediatr 2006;52(4):249-253

This article is approved for Continuing Respiratory Care Education credit. For information and to obtain your CRCE

(free to AARC members) visit www.rcjournal.com 